\title{
Influence of the maximum temperature of the thermal cycle on the properties and structure of the HAZ of steel S700MC
}

\author{
Jacek Górka \\ Welding Department - Silesian University of Technology, Poland
}

\begin{abstract}
In this paper an influence of simulated thermal cycle on properties and HAZ structure of $10 \mathrm{~mm}$ thick S700MC steel plates. Simulation and recording of thermal cycles were tested on laboratory stand equipped in thermovision camera and resistant heat source. Simulation was prepared for simple and complex thermal cycle. Specimens were tested on impact, strength test and also hardness and metallographic tests. Results of researches gave the possibilities to show an influence of welding thermal cycle on properties and HAZ structure of S700MC steel. It was possible also to indicate an optimal linear energy range for welding with high quality.
\end{abstract}

Keywords: - HAZ, S700MC steel welding, TMCP welding thermal cycle

\section{INTRODUCTION}

In recent years there has been a continuous increase in the global share of welded structures made of steel with increased and overall high yield of plasticity. Quality requirements in many industries such as shipbuilding, construction of roads and bridges, hydropower and nuclear power, construction of drilling platforms, pipelines and construction meant that the new technologies in steel metallurgy and metal forming and heat were developed and implemented allowing to achieve final products in the form of plates and tubes with high strength without reducing their plastic properties. Development of new grades of steel to weld and increase the requirements for welded constructions forced to undertake detailed studies on factors affecting the behavior of these materials during welding and structures made of them in operation. An example here may be welded thermomechanically rolled steels, particularly those that reach the yield strength of $700 \mathrm{MPa}$. The introduction of thermomechanically processed steels with high yield and relatively low carbon equivalent, will significantly reduce the time of welding works by reducing the preheating temperature, or even complete removal of this processing step, furthermore reduction of cross-sectional areas of structural elements, making welded structures with the same capacity will be more slender and lighter. The use of such steel will lower welding costs by reducing the cross section of joints, leading to a reduction in the consumption of additional materials, reducing the time of welding, straightening smaller outlays for construction and testing of joints [1,2]. Technical and economic aspects arising from the possibility of production of steel products from these steels in the energyefficient integrated production lines and their suitability for the construction of various structures, including those operating in extreme climatic conditions, decide on a lively interest in this group of materials science and improve their manufacturing technology and connecting using welding methods. The usefulness of these materials for the manufacture of welded structures often depends on factors which so far have only little been taken into account when assessing their weldability. A major problem in these steels is the effect of alloy micro additives (niobium, vanadium) on weldability and properties of welded joints. The role of the microadditives in these steels is reduced to formation, during the controlled rolling, the corresponding dispersion of carbides, nitrides and carbonitrides of niobium and vanadium increasing their mechanical properties by strengthening the precipitation and reduction of grain size [5-9]. Grain refinement also helps to maintain good plastic properties of steel. Weldability tests revealed that great difficulties during the welding of steels, thermomechanically treated may be caused by uncontrollable processes of MX type intermetallic phases separation (fine grain segregation of carbides/carbonitrides $\mathrm{Nb}(\mathrm{C}, \mathrm{N}), \mathrm{V}(\mathrm{C}, \mathrm{N})$ and others), which significantly lower the plastic properties of the welded joins and their crack resistance. It is also worth mentioning the negative influence of nitrogen, which is responsible for the ageing processes. The native material contains sufficient amount of active titan and aluminum, in comparison to the amount of nitrogen, which form stable and low solubility phases in austenite of the type: TiN and AlN. In the join the amount of titan will depend on the welding parameters and in the case of high level of nitrogen in the steel could be not sufficient to limit the ageing processes, what is causing deterioration the functional properties of the joins [10-15].

\section{RESEARCH}

The aim of this study was to investigate the effect of simulated welding thermal cycle on the properties of heat affected zone, thermomechanically treated steels with high plasticity yield S700MC, Table. 1, 2. 
Table 1. The chemical composition according to the regulation PN EN 10149-2 and mechanical properties of the S700 MC steel subjected to thermomechanical treatment used for cold moulding

\begin{tabular}{|c|c|c|c|c|c|c|c|c|c|c|c|}
\hline \multicolumn{12}{|c|}{ Chemical composition [\%] } \\
\hline $\begin{array}{l}\mathrm{C} \\
\max .\end{array}$ & $\begin{array}{c}\mathrm{Si} \\
\max .\end{array}$ & $\begin{array}{l}\mathrm{Mn} \\
\max .\end{array}$ & $\begin{array}{c}\mathrm{P} \\
\max \end{array}$ & $\begin{array}{c}\mathrm{S} \\
\max .\end{array}$ & $\begin{array}{l}\mathrm{Al}_{\text {całk. }} \\
\text { min. }\end{array}$ & $\begin{array}{c}\mathrm{Nb} \\
\max ^{*} .\end{array}$ & $\begin{array}{c}\mathrm{V} \\
\max .\end{array}$ & $\begin{array}{c}\mathrm{Ti} \\
\max .\end{array}$ & $\begin{array}{c}\mathrm{B} \\
\max .\end{array}$ & $\begin{array}{l}\text { Mo } \\
\text { max. }\end{array}$ & $\begin{array}{l}\mathrm{C}_{\mathrm{e}} \text { ** } \\
\max .\end{array}$ \\
\hline 0,12 & 0,60 & 2,10 & 0,008 & 0,015 & 0,015 & 0,09 & 0,20 & 0,22 & 0,005 & 0,50 & 0,61 \\
\hline \multicolumn{12}{|c|}{ Mechanical properties } \\
\hline \multicolumn{3}{|c|}{$\begin{array}{l}\text { Tensile strength } \\
\text { Rm, MPa }\end{array}$} & \multicolumn{3}{|c|}{$\begin{array}{l}\text { Yield limit } \\
\text { Re, } \mathrm{MPa}\end{array}$} & \multicolumn{3}{|c|}{$\begin{array}{c}\text { Elongation } \\
\mathrm{A}_{5}, \%\end{array}$} & \multicolumn{3}{|c|}{$\begin{array}{l}\text { Impact strength, } \\
\mathrm{J} / \mathrm{cm}^{2}\left(-20^{\circ} \mathrm{C}\right)\end{array}$} \\
\hline \multicolumn{3}{|c|}{822} & \multicolumn{3}{|c|}{768} & \multicolumn{3}{|c|}{19} & \multicolumn{3}{|c|}{135} \\
\hline
\end{tabular}

* - total amount of $\mathrm{Nb}, \mathrm{V}$ and Ti should be max. $0,22 \%$

** $\mathrm{C}_{\mathrm{e}}-$ carbon equivalent (1)

$$
C_{e}=C+\frac{M n}{6}+\frac{C r+N o+V}{5}+\frac{N i+C u}{15} .[\%]
$$

Table 2. The real chemical composition of the original S700 MC steel material

\begin{tabular}{|c|c|c|c|c|c|c|c|c|c|c|}
\hline \multicolumn{10}{|c|}{ Chemical composition, \% } \\
\hline $\mathrm{C}$ & $\mathrm{Mn}$ & $\mathrm{Si}$ & $\mathrm{S}$ & $\mathrm{P}$ & $\mathrm{Al}$ & $\mathrm{Nb}$ & $\mathrm{Ti}$ & $\mathrm{V}$ & $\mathrm{N}^{*}$ & $\mathrm{C}_{\mathrm{e}}$ \\
\hline 0,056 & 1,68 & 0,16 & 0,005 & 0,01 & 0,027 & 0,044 & 0,12 & 0,006 & 72 & 0,33 \\
\hline
\end{tabular}

* - N: the amount given in ppm, the nitrogen was measured using the high temperature extraction method

\section{Simulation and recording of welding thermal cycles}

The simulation of thermal cycles was carried out on a specially built test stand equipped with resistive heating source infrared camera with $50 \mathrm{~mm}$ lens and a computer with professional software, Figure 1. Sample distance from the camera lens was $460 \mathrm{~mm}$, and the video ran track at a height of 1550 [mm]. The simulation was carried out in air at the temperature of $20^{\circ} \mathrm{C}$ and humidity of $23,7 \%$.

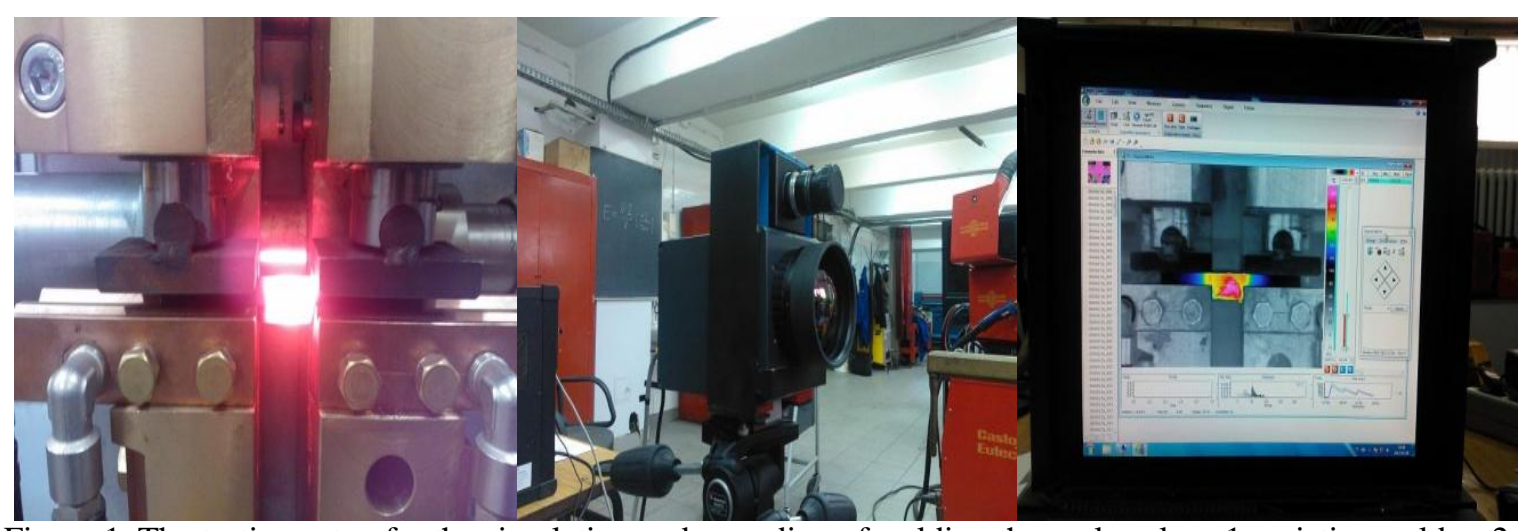

Figure 1. The testing setup for the simulation and recording of welding thermal cycles, 1-resistive welder, 2 thermal imager, 3 - a computer

Simulation studies of thermal cycles consisted of resistive heating of samples prepared for the impact test. Single thermal cycles were simulated at temperatures ranging from 400 to $1300{ }^{\circ} \mathrm{C}, 100{ }^{\circ} \mathrm{C}$ and the cycle complex. For each temperature three repeats were carried out. The course of the thermal cycle was recorded using a thermal imaging camera, but the results were processed based on a professional software. During the course of the study, the temperature was recorded as a function of time and the following parameters were established:

$\mathrm{T}_{\max }$ - specimen max. temperature,

$\mathrm{t}_{\mathrm{n}}$ - specimen heating time from $50^{\circ} \mathrm{C}$ up to $\mathrm{T}_{\max }$,

$\mathrm{t}_{8}$ - time for temperature decreasing below $800^{\circ} \mathrm{C}$,

$\mathrm{t}_{5}$ - time for temperature decreasing below $500{ }^{\circ} \mathrm{C}$,

$\mathrm{t}_{8 / 5}$ - specimen cooling time (temperatures range $800-500^{\circ} \mathrm{C}$ ), table 3 .

Example of thermal cycles recorded with thermograms are shown at Figure 2. 
Table 3. Results in characteristic points of thermal cycle

\begin{tabular}{|c|c|c|c|c|c|c|}
\hline $\begin{array}{c}\text { Cycle } \\
\text { designation }\end{array}$ & $\begin{array}{l}\text { Set temperature, } \\
{ }^{\circ} \mathrm{C}\end{array}$ & $\mathrm{T}_{\max ,}{ }^{\circ} \mathrm{C}$ & $\mathrm{t}_{\mathrm{n}}, \mathrm{s}$ & $\mathrm{t}_{8}, \mathrm{~s}$ & $\mathrm{t}_{5}, \mathrm{~s}$ & $\mathrm{t}_{8 / 5}, \mathrm{~s}$ \\
\hline 1 & 400 & 382 & 2,9 & - & - & - \\
\hline 2 & 500 & 518 & 2,7 & - & - & - \\
\hline 3 & 600 & 619 & 2,6 & - & - & - \\
\hline 4 & 700 & 720 & 2,8 & & & \\
\hline 5 & 800 & 807 & 2,7 & 3,3 & 16,4 & 13,1 \\
\hline 6 & 900 & 904 & 3,4 & 6,6 & 19,3 & 12,7 \\
\hline 7 & 1000 & 1017 & 4,3 & 12,7 & 23,9 & 11,2 \\
\hline 8 & 1100 & 1136 & 4,4 & 13,6 & 25,6 & 12,0 \\
\hline 9 & 1200 & 1203 & 5,7 & 15,9 & 29,2 & 13,3 \\
\hline 10 & 1300 & 1282 & 5,2 & 18,8 & 33,0 & 14,2 \\
\hline 11 & $\begin{array}{c}1300(800) / \\
1100(500) / 900\end{array}$ & 1299 & 6,6 & 36,0 & 68,2 & 32,2 \\
\hline 12 & $\begin{array}{c}1100(500) / \\
900(400) / 700\end{array}$ & 1080 & 3,6 & 12,1 & 59,4 & 47,3 \\
\hline 13 & $\begin{array}{c}1000(500) / \\
700(300) / 500\end{array}$ & 1068 & 4,2 & 11,8 & 58,6 & 46,8 \\
\hline
\end{tabular}
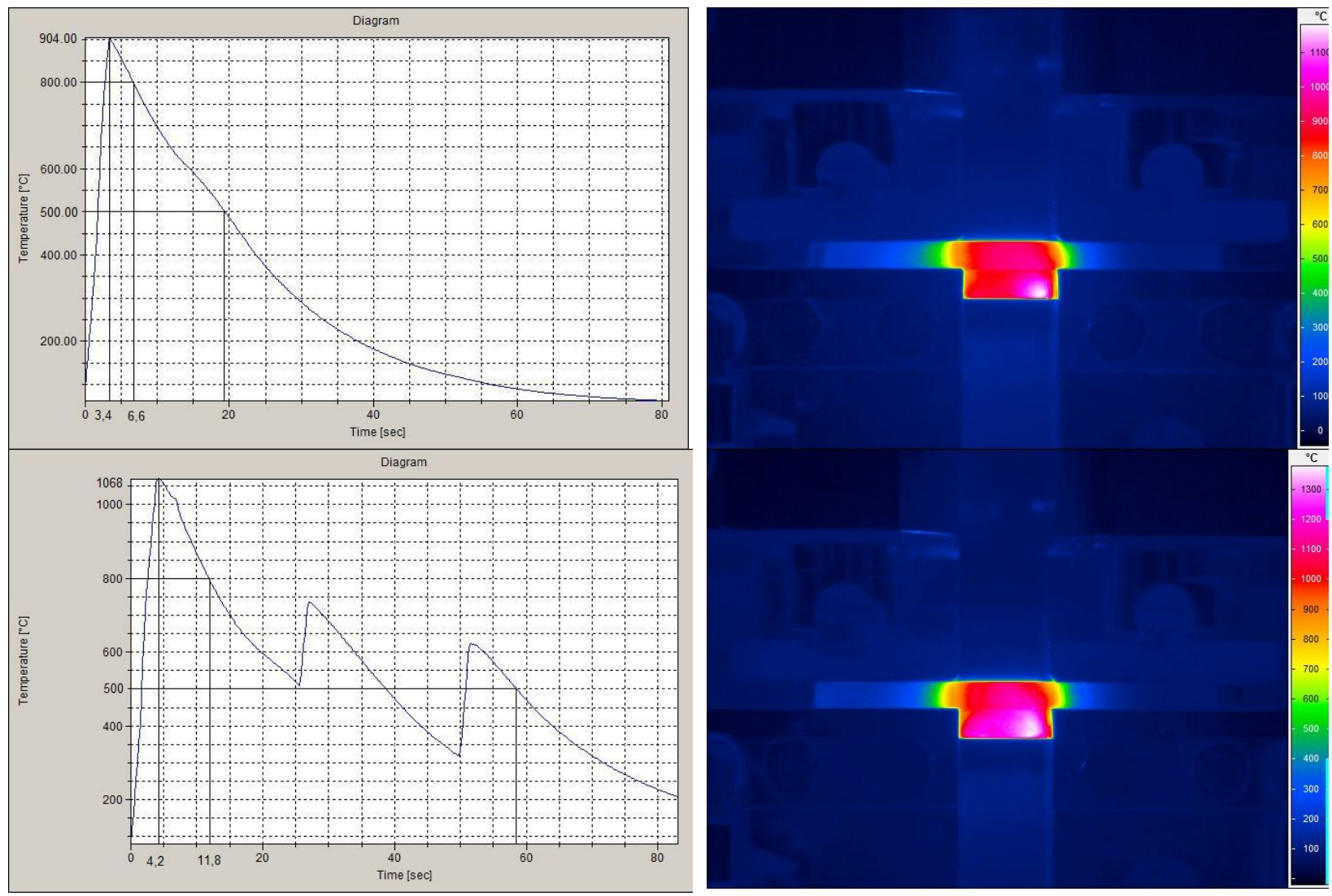

Figure 2. Welding thermal cycle $\mathrm{T}_{\max }=900^{\circ} \mathrm{C}$ and complex thermal cycle $\mathrm{T}_{\max }=1068{ }^{\circ} \mathrm{C}$ with thermogram

\section{Impact testing and hardness measurement}

Samples were obtained after measuring the thermal cycles were tested using Charpy V toughness at $30{ }^{\circ} \mathrm{C}$. After the fracture test, the visual assessment was carried out on the fractured surface, whereas on the polished front surface the Vickers hardness was measured using a load of $1 \mathrm{~kg}$. Table 4 shows the test results. 
Table 4. Impact tests, visual investigations and hardness measurement results

\begin{tabular}{|c|c|c|c|c|c|c|}
\hline $\begin{array}{c}\text { Cycle } \\
\text { designatio } \\
n \\
\end{array}$ & $\begin{array}{c}\text { Set } \\
\text { temperature, }{ }^{\circ} \mathrm{C}\end{array}$ & $\mathrm{T}_{\max ,}{ }^{\circ} \mathrm{C}$, & $\begin{array}{c}\text { Impact strenght } \\
\mathrm{KCV}^{*} \\
\left(-30^{\circ} \mathrm{C}\right) \mathrm{J} / \mathrm{cm}^{2}\end{array}$ & Fracture view & $\begin{array}{c}\text { Fracture } \\
\text { assessment }\end{array}$ & $\begin{array}{c}\text { Hardness } \\
\text { HV 1** }\end{array}$ \\
\hline 1 & 400 & 382 & 27 & & Mixed & 262 \\
\hline 2 & 500 & 518 & 33 & & Mixed & 260 \\
\hline 3 & 600 & 619 & 35 & & Mixed & 258 \\
\hline 4 & 700 & 720 & 37 & & Mixed & 260 \\
\hline 5 & 800 & 807 & 185 & & Plastic & 255 \\
\hline 6 & 900 & 904 & 308 & & Plastic & 240 \\
\hline 7 & 1000 & 1017 & 10 & & Fragile & 230 \\
\hline 8 & 1100 & 1136 & 6 & & Fragile & 227 \\
\hline 9 & 1200 & 1203 & 7 & & Fragile & 225 \\
\hline 10 & 1300 & 1282 & 6 & & Fragile & 230 \\
\hline 11 & $\begin{array}{c}1300(800) / \\
1100(500) / 900\end{array}$ & 1299 & 5 & & Fragile & 218 \\
\hline 12 & $\begin{array}{c}1100(500) / \\
900(400) / 700\end{array}$ & 1080 & 3 & & Fragile & 233 \\
\hline 13 & $\begin{array}{c}1000(500) / \\
700(300) / 500\end{array}$ & 1068 & 7 & & Fragile & 270 \\
\hline
\end{tabular}




\section{Microscopic examination}

In order to determine the effect of thermal cycle on the structural changes during intensive heating and cooling in a range of temperatures studied, the light microscope examination was carried out using a magnification of $1000 x$, the reagent used for digestion was nital. The example results of microscopic examinations for selected thermal cycles are shown in Figure 3.
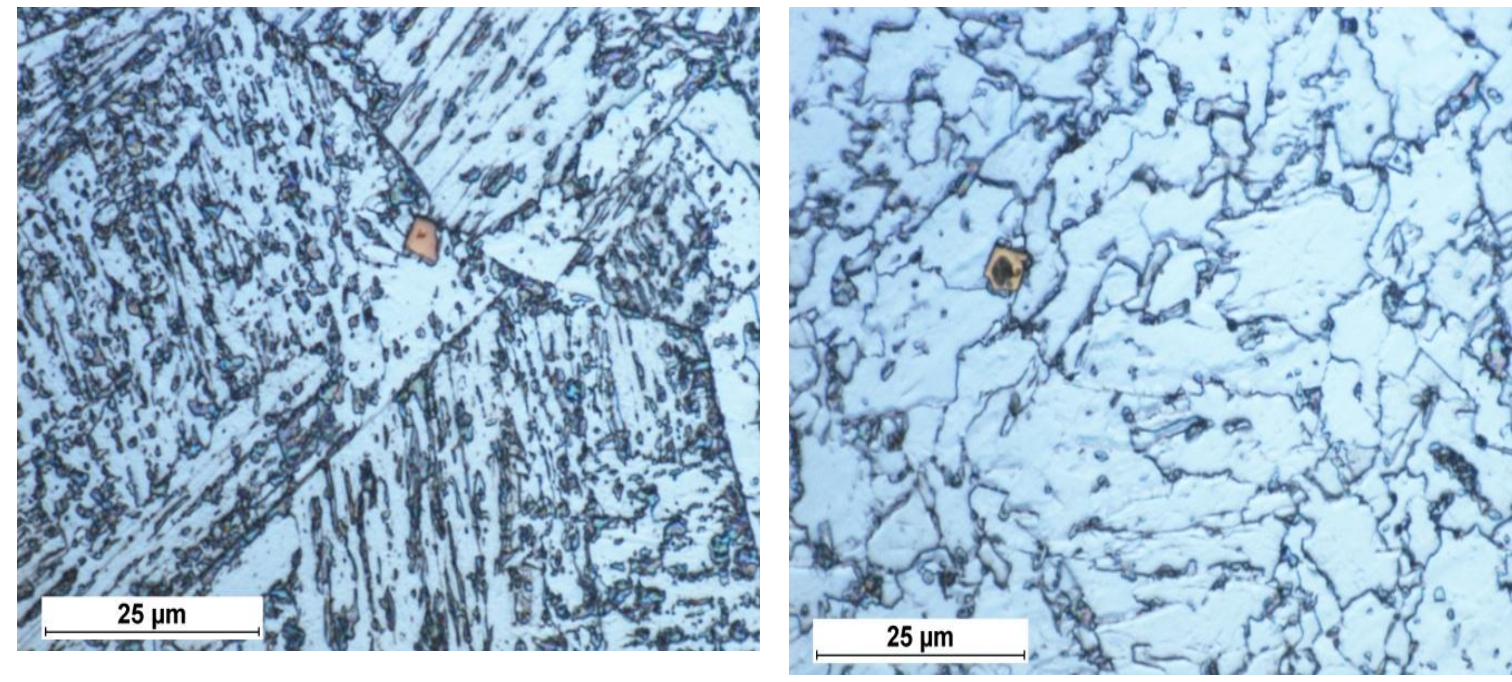

Figure 3. Microstructure of S700MC steel after welding thermal cycle $\mathrm{T}_{\max }=1136{ }^{\circ} \mathrm{C}$ and after welding complex thermal cycle $\mathrm{T}_{\max }=1068^{\circ} \mathrm{C}$

\section{THE ANALYSIS OF THE RESULTS}

In the processes of controlled thermo - plastic treatment of steel, microstructure parameters are shaped by setting appropriate for the chemical composition of steel and plastic deformation conditions of controlled cooling, and by the selection of the chemical composition of steel. Micro-additives of titanium, niobium and vanadium in microalloyed steels, strongly influence the grain growth, recrystallization of austenite and phase transformation as well as morphology of transformed products. Niobium carbide (NbC), giving off rapidly during plastic deformation, strongly inhibits the progress of recrystallization, under certain conditions, preventing its occurrence. Titanium forms a stable high-temperature titanium nitride (TiN), prevents the proliferation of austenite grains during heating of steel for plastic processing. To a lesser extent, affects the kinetics of recrystallization of austenite. Vanadium is released in the form of carbonitrides $\mathrm{V}(\mathrm{N}, \mathrm{C})$, moderately inhibited the progress of recrystallization, but strongly affects the morphology of the ferrite. The first phase which is liberated in a microalloyed steels is TiN. Beginning of the liberation of TiN takes place at about $1480{ }^{\circ} \mathrm{C}$. With lowering the temperature there is a gradual decrease in the content of titanium and nitrogen, dissolved in solid solution and the increase of TiN percentage. The total binding of titanium in TiN takes place at a temperature of about $1100\left[{ }^{\circ} \mathrm{C}\right]$. In the analysed samples of steel there is about $0,12 \%$ of titanium content, which is enough to bind $\mathrm{N}$. Next, during the cooling of steel with alloy micro-additives, the formation of $\mathrm{NbC}$ occurs. With decreasing the temperature a proportion of $\mathrm{NbC}$ in the solid solution increases, accompanied by reduction of dissolved $\mathrm{Nb}$ in austenite. In equilibrium conditions, virtually all $\mathrm{Nb}$ in $\mathrm{NbC}$ is bound at about $900{ }^{\circ} \mathrm{C}$. In the case of high cooling rates niobium contained in a supersaturated solid solution can be released in the transformation of $\gamma-\alpha$, or in the ferrite up to a temperature of $500{ }^{\circ} \mathrm{C}$. Thermal cycles occurring during the welding process deviate significantly from equilibrium processes. The size and intensity of heating and cooling of heat-affected zone is dependent on welding heat input. A built testing system allowed the simulation of welding thermal cycles of cooling time $\mathrm{t}_{8 / 5}$ at the level of 11 to $14 \mathrm{~s}$ for simple cycles and from 32 to $50 \mathrm{~s}$ for complex cycles. The analysis of thermal cycles confirmed the high reproducibility of the results and the possibility to use this approach to the research of this type. The analysis results of toughness, microscopic examination and measurement of hardness showed that in the case of thermomechanically treated steel intensity of welding thermal cycle strongly influences the properties and structure of the heat affected zone. In the case of warm-HAZ in the temperature range $400-700{ }^{\circ} \mathrm{C}$ there is a slight grain growth and partial recrystallization which results in lower toughness compared to the base material and a reduction in hardness of about $260 \mathrm{HV} 1$, where the hardness of the parent material is at $280 \mathrm{HV} 1$. Toughness of HAZ during heating in the temperature range $400-700{ }^{\circ} \mathrm{C}$ is reduced to about $37 \mathrm{~J} / \mathrm{cm}^{2}$, with the toughness of parent material of about $80 \mathrm{~J} / \mathrm{cm}^{2}$. Thermal cycle in this temperature range does not cause structural changes and phase changes in the HAZ. During heating of samples in the temperature range $800-900{ }^{\circ} \mathrm{C}$, there is a phase transition $\alpha-\gamma$, establishing 
the structure of austenite with a small grain, and a rapid cooling (the times of the order of $12 \mathrm{~s}$ ) gives a finegrained ferritic-bainitic structure with a very high impact strength up to $200 \mathrm{~J} / \mathrm{cm}^{2}$. The hardness of the HAZ area is about $265 \mathrm{HV} 1$. High heat cycles in the temperature range $1000-1300{ }^{\circ} \mathrm{C}$ and a series of complex cycles $1300(800) / 1100(500) / 900$ and 1100(500)/900(400)/700 result in the HAZ zone formation of large austenite grains, which, after cooling, form a bainite structure with a very low impact strength: 3 to $5 \mathrm{~J} / \mathrm{cm}^{2}$. This rapid decrease in toughness is associated with intense dissolution of MX phases in austenite grains during heating and during cooling using uncontrolled processes of separation in various fields of grain and on its borders. The hardness of these areas is reduced relative to the base material and is about $230 \mathrm{HV} 1$. In the case of a complex series of $1000(500) / 700(300) / 500$ as in the case of individual cycles in the temperature range $800-900{ }^{\circ} \mathrm{C}$ there is a beneficial process of fragmentation and uniform grain structure in terms of phase resulting in an increase in toughness to $220 \mathrm{~J} / \mathrm{cm}^{2}$ and increase in the hardness to $270 \mathrm{HV} 1$. The microscopy analysis revealed in the heated HAZ zone a presence of nitrogen phases, indicating that in the investigated steel there is sufficient amount of titanium needed to bind to free nitrogen, which is related to reduced aging processes, Figure 4.
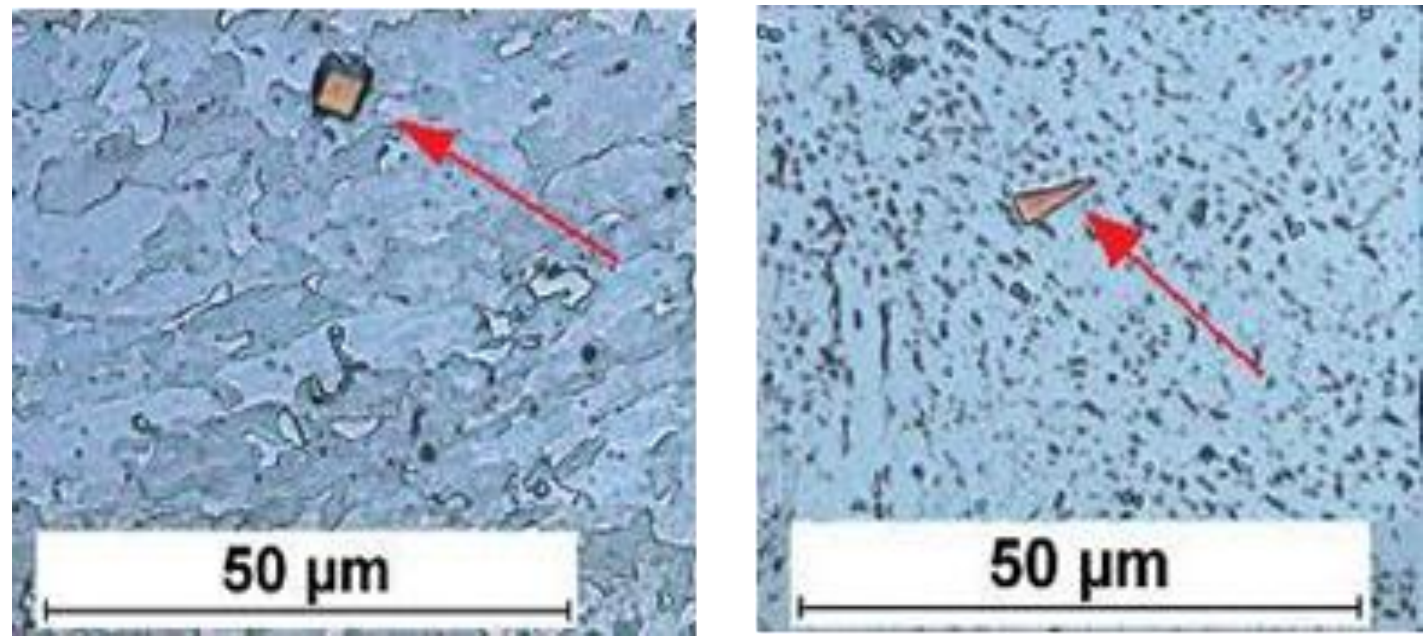

Figure 4. View of nitrides in the $\mathrm{HAZ}$ area, thermal cycle $\mathrm{T}=700^{\circ} \mathrm{C}$ and complex thermal cycle $\mathrm{T}=$ $1300{ }^{\circ} \mathrm{C}$

\section{CONCLUSION}

The study showed that there is a possibility to use a purpose built system to simulate simple and complex thermal cycles of S700 MC steel in specific ranges of the cooling time $t_{8 / 5}$. Analysis of the results of the study showed that the welding thermal cycle strongly influences the structural changes and phase in the $\mathrm{HAZ}$ zone of S700 MC steel. Areas of HAZ heated to high temperatures above $1000{ }^{\circ} \mathrm{C}$, show a sudden drop of toughness to unacceptable levels of impact strength $\left(27 \mathrm{~J} / \mathrm{cm}^{2}\right)$. This sharp decrease in toughness is associated with uncontrolled separation processes of MX phases and dissolution of carbides, niobium and vanadium carbonitrides in austenite during heating. The study also showed that the chemical composition of steel and especially titanium and aluminum content is sufficient to bind in the HAZ free nitrogen and reduce the aging process. The control of the amount of heat introduced into the joint area during welding will reduce the adverse separation processes in the weld and HAZ which will ensure adequate toughness of the connection. Precise knowledge of the phenomena occurring in the HAZ during the thermal cycle can impact the ability to control properties and structure of the welded joint.

\section{ACKNOWLEDGMENT}

This work was funded through the following research grant: „Control properties and structure of steel joints for thermomechanically processed high yield”, nr N N507 321040, Silesian University of Technology in Gliwice.

\section{REFERENCES}

[1] Park K. S., Cho Y. H.: Comparison of fatigue properties of welded TMCP steels and normalized steel, Pohang University of Science and Technology, Pohang, Korea 2003.

[2] TMCP steel plates for building structures. Nippon Steel Corporation.

[3] Sueyoshi T., Ishikawa N., Iwase A.: The role of niobium in the retardation of the early stage of austenite recovery in hot-deformed steels. Materials Science and Engineering, vol. 250 (1998), No. 1, pp. 2-7.

[4] Yurioka N.: TMPC steels and their welding. Welding in the World. Vol. 35, 6/1995 
[5] Zając Z., Langeborg R., Siwecki T.: The role of nitrogen in microalloyed steels. Microalloying 95. Pitsburg 1995.

[6] Gladman T.: The physical metallurgy of mikroalloyed steels, The Institute of Materials, Cambridge University Press, Cambridge 1997.

[7] Rauch R., Schütz H.: Advantages of TM-steels in welding fabrication, MIS IX-1947-91

[8] Górka J.: Influence of welding thermal cycling on the join properties of S700MC steel treated using thermomechanical method, 15th International Conference on Experimental Mechanics, 22-27 June 2012, Porto, Portugal, pp. 197-198.

[9] Lisiecki A., Mańka J.: Welding S420MC steel sheets with high yield of high power laser diode, Bulletin of the Institute of Welding, Poland, nr 3/2012, pp. $67-71$.

[10] Hildebrand J., Werner F.: Change of structural condition of welded joints between high-strength finegrained and structural steels, Journal of civil engineering and management. 2004, No 2, 87-95

[11] Hakansson K.: Weld Metal Properties for Extra High Strength Steels, Report 2002 - August, Division of Welding, Department of Production Engineering, The Royal Institute of Technology

[12] Meester B.: The weldability of modern structural TMCP steel. ISIJ International, vol. 37, 1997, No. 6, pp. $537-551$

[13] Bang K.S., Kim W.Y.: Estimation and prediction of HAZ softening in thermomechanically controlled rolled and accelerated - cooled steel. Welding Journal, vol. 81 (2002), No. 8, pp. 174-179

[14] Guide to weldability and metallurgy of welding of steels processed by termomechanical rolling of by accelerated cooling, MIS IX-1949-91

[15] Klimpel A., Lisiecki A. et al.: Numerical and experimental determination of weld pool shape during highpower diode laser welding. SPIE Proceedings Vol. 5229, Laser Technology VII: Applications of Lasers, 6 October 2003, pp. 247-250 